\title{
Proteasomal activities in the claw muscle tissue of European lobster, Homarus gammarus, during larval development
}

\author{
Sandra Götze $\cdot$ Reinhard Saborowski
}

Received: 30 August 2010/Revised: 25 March 2011/Accepted: 27 March 2011/Published online: 1 May 2011

(c) Springer-Verlag 2011

\begin{abstract}
Decapod crustaceans grow discontinuously and gain size through complex molt processes. The molt comprises the loss of the old cuticle and, moreover, substantial reduction and re-organization of muscles and connective tissues. In adult lobsters, the muscle tissue of the massive claws undergoes significant atrophy of $40-75 \%$ before ecdysis. The degradation of this tissue is facilitated by calcium-dependent proteases and by the proteasome, an intra-cellular proteolytic multi-enzyme complex. In contrast to the adults, the involvement of the proteasome during the larval development is yet not validated. Therefore, we developed micro-methods to measure the $20 \mathrm{~S}$ and the $26 \mathrm{~S}$ proteasomal activities within $\mathrm{mg}$ - and sub-mg-quantities of the larval claw tissue of the European lobster, Homarus gammarus. Within the three larval stages (Z1-3) we distinguished between sub-stages of freshly molted/hatched (post-molt), inter-molt, and ready to molt (pre-molt) larvae. Juveniles were analyzed in the post-molt and in the inter-molt stage. The trypsin-like, the chymotrypsin-like, and the peptidyl-glutamyl peptide hydrolase activity (PGPH) of the $20 \mathrm{~S}$ proteasome increased distinctly from freshly hatched larvae to pre-molt Z1. During the Z2 stage, the activities were highest in the post-molt animals, decreased in the inter-molt animals and increased again in
\end{abstract}

Communicated by G. Heldmaier.

S. Götze · R. Saborowski ( $₫)$

Alfred Wegener Institute for Polar and Marine Research,

Functional Ecology, PO Box 120161,

27515 Bremerhaven, Germany

e-mail: Reinhard.Saborowski@awi.de

S. Götze

Phillipps-Universität, FB Biologie, Karl-von-Frisch-Straße 8,

35043 Marburg, Germany the pre-molt animals. A similar but less distinct trend was evident in the $\mathrm{Z3}$ stages. In the juveniles, the proteasomal activities decreased toward the lowest values. A similar pattern was present for the chymotrypsin-like activity of the $26 \mathrm{~S}$ proteasome. The results show that the proteasome plays a significant role during the larval development of lobsters. This is not only reflected by the elevated activities, but also by the continuous change of the trypsin/ chymotrypsin-ratio which may indicate a shift in the subunit composition of the proteasome and, thus, a biochemical adjustment to better cope with elevated protein turnover rates during larval development.

Keywords Lobster larvae - Molt - Claws .

Muscle atrophy $\cdot 20 \mathrm{~S}$ and $26 \mathrm{~S}$ proteasome

\section{Introduction}

Crustaceans have to shed their exoskeleton when they grow. To be able to slide out of their old shell, they have to reduce muscle tissue. This mold-induced muscle atrophy is most distinct in the large claws of the thoracopods (Mykles 1999a) where the muscle tissue may be degraded by 40-75\% (Skinner 1966; Shean and Mykles 1995). Although the muscle is weakened, its contractile function remains largely intact. This is due to the fact, that the muscle fibers and myofibrils are less degraded but, instead, the filament packing is compressed. So, the ratios of thin to thick myofilaments decrease from 9:1 to 6:1 (Mykles and Skinner 1981). This reduction and re-organization is accompanied by a drastic increase in both protein degradation and protein synthesis (e.g.,El Haj et al. 1996). The high protein turnover rate seems to be necessary to perform the complex remodeling process. Two different but 
complementary proteolytic systems are mainly responsible for the muscle degradation in lobsters: calcium-dependent calpain-like proteases and proteasome (Mykles 1990, 1999b; Mykles and Haire 1991; Koenders et al. 2002).

The proteasome is a highly conserved multi-catalytic protease complex, which is present in prokaryotes as well as in all tissues of eukaryotes (Baumeister et al. 1998; De Mot et al. 1999). Since the majority of redundant proteins and peptides are degraded via the ATP/ubiquitin-dependent proteasomal pathway, the proteasome seems to hold a regulatory key position within cells (Hochstrasser 1995). It is involved in, e.g., cell-cycle control, cell differentiation, apoptosis, antigen processing and signal transduction (Voges et al. 1999). The proteasome of eukaryotes consists of a core complex, denoted as $20 \mathrm{~S}$ proteasome $(\sim 700 \mathrm{kDa})$, which forms together with two regulatory subunits, the $26 \mathrm{~S}$ proteasome $(\sim 2.5 \mathrm{MDa})$. The catalytic centers are located within the barrel-shaped 20S core unit (Baumeister et al. 1998).

The $20 \mathrm{~S}$ core complex is made up of 28 subunits, which are organized in four-stacked rings. The two outer rings consist of seven different $\alpha$-subunits and form a pore on each side, which is accessible only by unfolded proteins or short polypeptides. The two inner rings consist of seven different $\beta$-subunits and only they buid up the hydrolytic chamber. However, only three subunits of each $\beta$-ring are proteolytically active. The sites are named after their preferred cleaving mechanism: the trypsin-like site $(\beta 2)$ cleaves preferentially after basic residues, the chymotrypsin-like site $(\beta 5)$ cleaves after large hydrophobic residues, and the peptidyl-glutamyl-peptidase hydrolase-like (PGPH) site, recently more correctly referred to as caspase-like site $(\beta 1)$, cleaves after acidic residues. The subunit composition of the proteasome can vary depending on, e.g., posttranslational modification, on the target tissues, or the age of the organism (Frisan et al. 1998; Dahlmann et al. 2000; Husom et al. 2003). Depending on the subunit composition, the proteasome may display different catalytic cleavage preferences.

The early developmental stages of crustaceans are subjected to immense morphological and anatomical changes through a series of rapidly succeeding molts. Within about 14 days, the larvae pass three zoea stages and molt into the first juvenile stage (Charmantier et al. 1991; Schmalenbach and Fanke 2010). Similar to the adults, the larvae have to reduce and re-organize their muscles as well as the connective tissue. So far, only limited information is available about the mechanisms, which control these vital physiological processes in crustacean larvae.

We raise the hypothesis that the proteasome is already involved in the molts between the larval stages. Therefore, the aim of the present work was to study the contribution of the $20 \mathrm{~S}$ and the $26 \mathrm{~S}$ proteasome during larval development of European lobsters (Homarus gammarus). As target organ, we chose the claws of the larvae because the muscle tissue in these claws most probably undergoes similar modification as in adults. Moreover, the claws consist mainly of muscle and connective tissue and, thus, have the advantage of providing solely the proteasomal enzymes of interest. Using entire larvae would be detrimental because the comparatively huge midgut gland would contribute highly active digestive enzymes, including trypsin and chymotrypsin. Since these enzymes are able to degrade the substrates used for proteasomal measurements, the digestive enzymes would interfere with the proteasomal enzymes or mask their activities. However, since the claws are extremely small, weighing mostly less than $2 \mathrm{mg}$, we first had to establish sensitive micro-assays to guarantee reliable and reproducible enzyme measurements. We focused our studies on the ontogenetic changes and molt cycles of individual larvae. Crude extracts were prepared from claws and the proteasomal activities were verified by the highly specific effectors epoxomicin and PA28 (Mykles 1996; Meng et al. 1999; Kisselev and Goldberg 2001). The results will help to better understand larval development and those processes that influence molt success in early developmental stages of decapod crustacea.

\section{Materials and methods}

\section{Maintenance and rearing of lobster larvae}

Lobster larvae of all three zoea stages (Z1-Z3) as well as the first juvenile stage (J1) were obtained from the lobster rearing facility of the Marine Station Helgoland and shipped to the laboratories in Bremerhaven. Immediately after arrival, the larvae were separated and maintained individually in 100-ml beakers filled with filtered natural seawater. The water temperature ranged between 17 and $19^{\circ} \mathrm{C}$. The seawater was exchanged daily and the larvae were fed with freshly hatched nauplii of the brine shrimp Artemia salina. The overall mortality of the lobster larvae in the rearing experiments was less than $10 \%$.

One group of larvae $(n=15)$ was allowed to grow up until they reached the juvenile stage. This approach was used to determine the duration of the larval stages at the given experimental conditions (Table 1). Additional data about the duration of larval development were provided by Schmalenbach and Fanke (2010).

The samples were taken after molting (post-molt), during the inter-molt phase (inter-molt), and before the next molt (pre-molt) of each stage. Z1 larvae were sampled after hatching $(\mathrm{Z} 1 / 1)$ to obtain the post-molt individuals. When the developmental times were unknown, the larvae were first raised until they molted into the subsequent stage. 
Table 1 Developmental time of the larval stages (mean $\pm \mathrm{SD}, n=15$ ) and sampling schedule after hatch or molt, respectively, of the larval and juvenile stages

\begin{tabular}{lllll}
\hline Stage & Duration (days) & \multicolumn{3}{l}{ Time of sampling (days) } \\
\cline { 3 - 5 } & & Hatched/post-molt & Inter-molt & Pre-molt \\
\hline Zoea 1 & $4.3 \pm 0.8$ & Max. 12 h after hatch & $3.0 \pm 0.5$ & \pm 1 day before molt \\
Zoea 2 & $8.1 \pm 2.4$ & Max. 12 h after molt & $3.0 \pm 0.5$ & \pm 1 day before molt \\
Zoea 3 & $12.8 \pm 1.1$ & Max. 12 h after molt & $5.5 \pm 0.5$ & \pm 1 day before molt \\
Juvenile 1 & $20.3 \pm 3.2$ & Max. 12 h after molt & $10.0 \pm 0.5$ & (not sampled) \\
\hline
\end{tabular}

Thereafter, controlled sampling could be performed after defined periods.

The post-molt individuals were sampled at the latest $12 \mathrm{~h}$ after hatching or molting, but preferably as early after ecdysis as possible. The inter-molt individuals were sampled after they passed half of the predicted duration of the respective stage. To sample the pre-molt animals in due time, the larvae of the respective batch were controlled for the first animal to molt into the next stage. When this happened, it was assumed that the larvae of this batch were also at a stage shortly before the molt and, consequently, were sampled. A detailed schedule illustrating the molt intervals and the sampling strategy is shown in Fig. 1.

\section{Extract preparation}

From single larvae of each molting stage, both claws were completely excised, briefly blotted dry on filter paper and transferred into a reaction tube. The claws were weighed and homogenized in $45 \mu \mathrm{l}$ of homogenizing buffer (20 mmol $\mathrm{l}^{-1}$ Tris/HCl, $1 \mathrm{mmol} \mathrm{l}^{-1}$ EDTA, $5 \mathrm{mmol} \mathrm{l}^{-1}$ $\mathrm{MgCl}_{2}, \mathrm{pH}$ 7.5) using a micro-pestle. Subsequently, the extracts were centrifuged for $10 \mathrm{~min}\left(9000 \mathrm{~g}, 4^{\circ} \mathrm{C}\right)$ and split into two samples of $20 \mu \mathrm{l}$ each. The aliquots were stored at $-80^{\circ} \mathrm{C}$ until further analysis.
Proteasomal activities

The proteasomal activities were investigated in claw muscle extracts of lobster larvae from each molt stage ( $n=6-10$ individuals).

The trypsin-like, chymotrypsin-like and peptidylglutamyl peptide hydrolase activities (PGPH) of the 20S proteasome were assayed by using the fluorogenic substrates Boc-Leu-Arg-Arg-AMC (PeptaNova, 3140), Suc-Leu-LeuVal-Tyr-AMC (Enzo Life Sciences, P-802) and Z-LeuLeu-Glu-AMC (Enzo Life Sciences, 9345). Additionally, the trypsin-like and the chymotrypsin-like activities were verified by inhibition of the enzymes by the highly specific inhibitor epoxomicin (PeptaNova, 4381-0.02). The PGPH activity was not inhibited but, instead, activated by the endogenous regulatory complex PA28 (11S regulatory subunit, Enzo Life Sciences, 9420-0025). The chymotrypsin activity of the $26 \mathrm{~S}$ proteasome was determined with the substrate for the chymotrypsin-like activity and with the inhibitor. The only difference was the composition of the assay buffer. The buffer for measuring the $20 \mathrm{~S}$ proteasome contained $0.1 \mathrm{M}$ Tris at a $\mathrm{pH}$ of 8 , while the buffer for measuring the $26 \mathrm{~S}$ proteasome contained 5 mmol $\mathrm{l}^{-1}$ Tris, $4 \mathrm{mmol} \mathrm{l}^{-1} \mathrm{HCL}, 5 \mathrm{mmol} \mathrm{l} \mathrm{MgCl}_{2}$ and $2 \mathrm{mmol}^{-1}$ ATP at the same $\mathrm{pH}$.

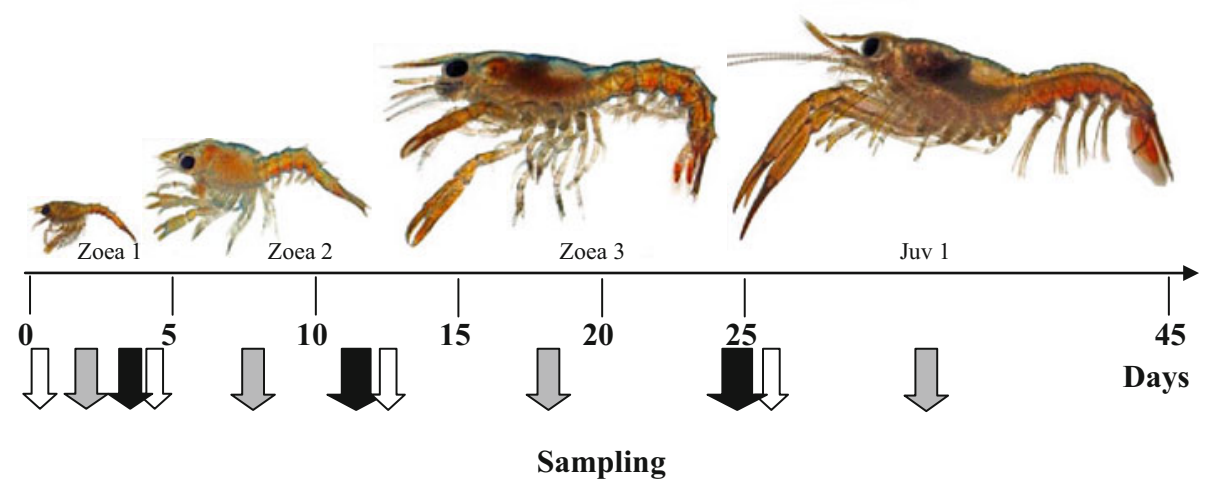

Fig. 1 Stage duration of the larvae and the sampling intervals (in days). The hollow white arrows indicate when the post-molt individuals were sampled, the gray arrows indicate the sampling of the inter-molt individuals and the black arrows the sampling of the pre-molt individuals. The sizes of the larvae are not shown in scale. The lengths (from the rostrum to the tip of the telson) ranged from 9 $\mathrm{mm}$ in Zoea 1 to $13 \mathrm{~mm}$ in Zoea 3. The first juvenile stage was on average $16 \mathrm{~mm}$ long 
The sensitivity of the 20S proteasome against epoxomicin as well as its specificity was first examined with claw muscle tissue of adult European lobster samples. The applied concentrations of epoxomicin ranged for the chymotrypsin-like activity from 2.5 to $50 \mu \mathrm{mol} \mathrm{l}^{-1}$ and for the trypsin-like activity from 10 to $100 \mu \mathrm{mol} 1^{-1}$. Blanks were run to determine the auto-fluorescence of the substrate and of the inhibitor, respectively. Additionally, one approach served as control for the level of uninhibited activity.

The specificities of the effectors, epoxomicin and PA28, were determined by comparing the grade of inhibition or the grade of activation in samples containing 20S proteasome or gastric fluid, respectively. The gastric fluid is rich in digestive enzymes such as trypsin, chymotrypsin and other proteases, but does not contain proteasome. Digestive trypsin and chymotrypsin are capable of degrading the same fluorogenic substrates as the proteasome. However, in contrast to the proteasome, the gastric enzymes should neither be affected by epoxomicin nor by PA28. The gastric fluids of three adult European lobsters were obtained directly from the stomach with a syringe connected to a plastic tube. The samples were centrifuged for $15 \mathrm{~min}$ at $1,3000 \mathrm{~g}$ and $4^{\circ} \mathrm{C}$ to remove food residues and were diluted 1:20 with demineralized water (a. dem.) before they were applied into the reaction tubes. First, the trypsin and the chymotrypsin activities of the gastric fluids were determined to obtain the unaffected level of activity. Concurrently, assays were run with epoxomicin with concentrations of $100 \mu \mathrm{mol} 1^{-1}$ for the trypsin-like activity and $5 \mu \mathrm{mol} \mathrm{l}^{-1}$ for the chymotrypsin-like activity. Additionally, it was investigated whether the gastric enzymes were able to degrade the PGPH substrate and whether the activity can be enhanced by PA28. The PA28 concentration amounted to $4 \mu \mathrm{g} \mathrm{ml}^{-1}$.

\section{Enzyme micro-assays with the NanoDrop device}

Fluorometric enzyme micro-assays were carried out with a NanoDrop device as described by Götze and Saborowski (2011). The instrument requires only $2 \mu \mathrm{l}$ of reaction mixture. Accordingly, the total volume of the reaction mixture was reduced to $25 \mu \mathrm{l}$. It contained $17.5 \mu \mathrm{l}$ buffer, $5 \mu \mathrm{l}$ enzyme solution (sample), $1.25 \mu \mathrm{l}$ of substrate solution (final concentration for the trypsin-like activity was $0.75 \mathrm{mmol} \mathrm{l}^{-1}$, for the chymotrypsin-like activity $0.5 \mathrm{mmol}^{-1}$ and for the PGPH-like activity $1.0 \mathrm{mmol} \mathrm{l}^{-1}$ ), and, in case, $1.25 \mu \mathrm{l}$ of the inhibitor epoxomicin or the activator PA28 (final concentration 100 and $5 \mu \mathrm{mol} 1^{-1}$, respectively). All substrates, except PA28 which was delivered already in solution, were dissolved in dimethyl sulfoxide (DMSO) and prepared as 10- or 20-fold stock solutions freshly before use. The reaction mixtures were incubated in micro-tubes at $37^{\circ} \mathrm{C}$. The released fluorescence was measured exactly after $1 \mathrm{~h}$, while $2 \mu \mathrm{l}$ of the reaction mixture was taken from the reaction tubes and pipetted onto the optical pathway of the NanoDrop 3300 device (PeqLab). The fluorescence was measured at $365 \mathrm{~nm}$ (ex) and $437 \mathrm{~nm}$ (em). Blanks containing only buffer and the substrate but no enzyme were run in parallel to control substrate autolysis.

\section{Protein assay}

Dissolved protein was quantified after Bradford (1976) with a commercial dye reagent (BioRad, 500-0006). The reagent was diluted 1:5 with a. dem. before use. Bovine serum albumin (BSA, BioRad, 76290A) was used as standard. Increasing amounts of the standards from 0 to $5 \mu \mathrm{g}$ were applied in duplicate onto a 96-well plate and filled up with a. dem. to $25 \mu$ l. Samples $(5 \mu \mathrm{l})$ were applied in duplicate and filled up to $25 \mu$ l. The reactions were started with the addition of $125 \mu \mathrm{l}$ of the diluted dye reagent (1:5 with a. dem.) to each standard and each sample. After 5 min of incubation, the optical density was read at $600 \mathrm{~nm}$ with a microplate reader (Thermo Scientific, Multiscan SF).

\section{Quantification and data analysis}

Trypsin and chymotrypsin activities were measured with and without the inhibitor epoxomicin. Only the shares of the enzyme activities which were inhibited were regarded as true proteasomal activities. The relative fluorescence (RF) obtained from the enzymatic measurements was quantified in relation to the protein content of the sample

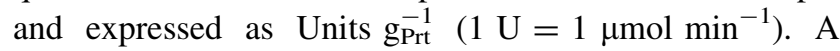
calibration curve was established with 7-amino-4-methylcoumarin (AMC, Fluka, 08440). The AMC was dissolved in DMSO and prepared as tenfold stock solutions for concentrations from 0.025 to $10 \mu \mathrm{mol} \mathrm{l}^{-1}$. Then, $2.5 \mu \mathrm{l}$ of the particular concentration was added to $22.5 \mu \mathrm{l}$ of assay buffer and the fluorescence was measured with the NanoDrop device. Each concentration was measured in five replicates, which were used to calculate a calibration curve.

The data were expressed as mean specific activities $\left(\mathrm{U} \mathrm{g}_{\mathrm{Prt}}^{-1}\right)$ and the standard errors of the means (SEM). Data sets were subjected to a one-way ANOVA followed by a Tukey HSD test (Statistica 7.1, Systat Software, Inc.). Significant differences between groups were indicated by different letters when $p$ values $\leq 0.05$. Graphs were created with the program SigmaPlot 10.0 (Systat Software, Inc.).

\section{Results}

Weight and protein content

The size, fresh weight and protein content of the claws increased significantly during the development of the 
lobster larvae. The fresh weight and protein content displayed a statistically significant correlation (Fig. $2, r^{2}=$ $0.6, n=110, p<0.001$ ).

The weight of a pair of claws increased significantly from stage to stage (Fig. 3). The claws of the Z1 larvae weighed on average $0.63 \mathrm{mg}$. The weight increased until the first J1 stage to about $2.9 \mathrm{mg}$. The protein content rose continuously from $15.9 \mu \mathrm{g}$ in $\mathrm{Z} 1$ to $23.7 \mu \mathrm{g}$ in Z3. Between $\mathrm{Z} 3$ and $\mathrm{J} 1$, the protein content increased about 2.3-fold to an average of $55.3 \mu \mathrm{g}$.

The weight and the protein content did not change significantly within the three molt stages of Z1 (Fig. 3). Both values, however, increased in $\mathrm{Z} 2$ larvae significantly. This trend continued for the fresh weight within the Z3 larvae. The claws of pre-molt $\mathrm{Z} 3$ individuals were significantly heavier than those of post-molt $\mathrm{Z} 3$. The protein content rose from the post-molt to the inter-molt individuals significantly, but the pre-molt animals possessed less protein. The two juvenile molt stages showed significantly higher weights than the larvae. The juvenile stages did not differ in their protein content.

\section{Inhibition and activation of proteasomal activities}

The trypsin-like and the chymotrypsin-like $20 \mathrm{~S}$ proteasomal activities of the claw muscle extracts of the adult European lobsters were significantly inhibited by epoxomicin (Fig. 4).

Over $93 \%$ of the chymotrypsin-like activity was inhibited when epoxomicin was present in the lowest concentrations of $2.5 \mu \mathrm{mol} \mathrm{l^{-1 }}$. Around $50 \%$ of the trypsin-like activity was inhibited by $10 \mu \mathrm{mol} \mathrm{l}^{-1}$ epoxomicin. Increasing concentrations of epoxomicin did not considerably enhance the inhibition of the chymotrypsin-like

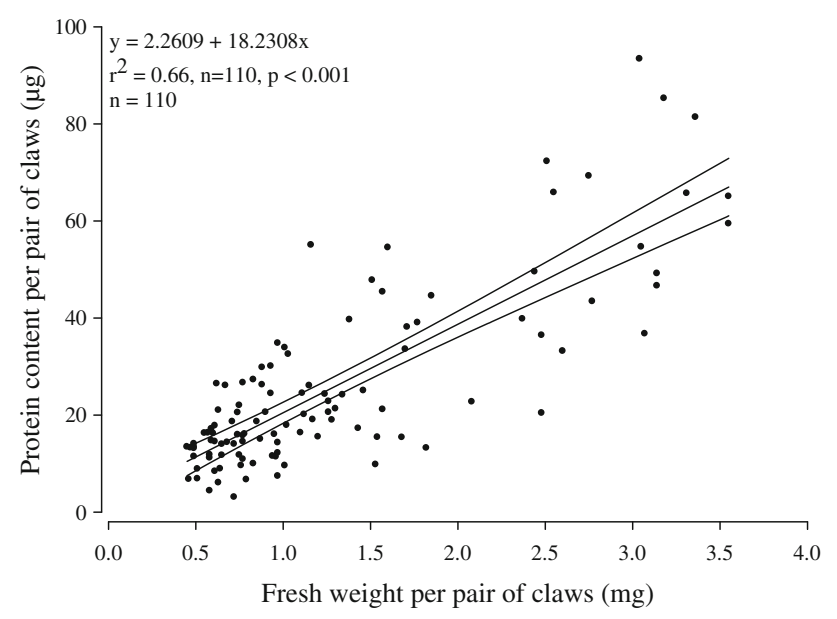

Fig. 2 Correlation between the fresh weight and the protein content per pair of claws $(n=110)$. Indicated is the regression line with the confidence intervals $(95 \%)$

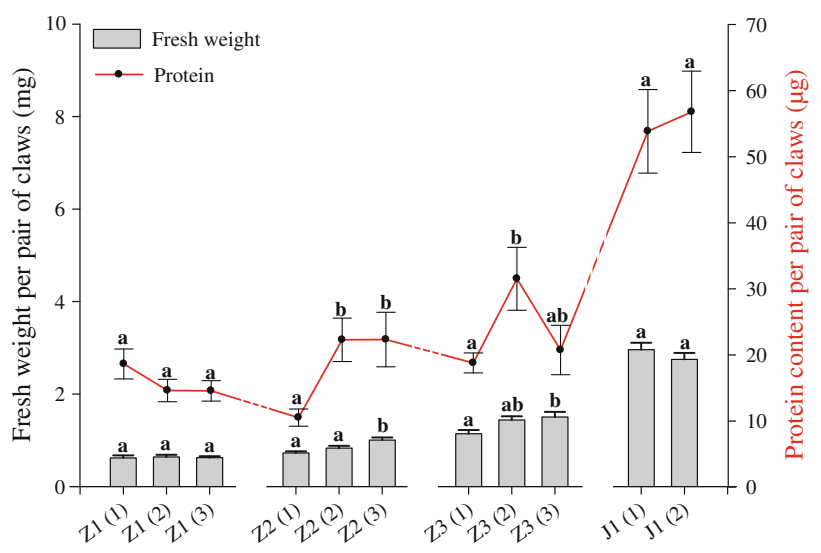

Fig. 3 Fresh weight and the protein content of one pair of claws of the developmental stages. The bars represent the average fresh weight of a pair of claws and the line represents the average protein content of a pair of claws. The values are expressed as mean \pm SEM $(n=10)$. Different letters indicate significant differences within the respective stages $(p<0.05)$. Z1-Z3, Zoea $1-Z o e a ~ 3$; J1, Juvenile 1 . The numbers 1-3 in brackets indicate the molt stage: (1), freshly hatched or post-molt stage; (2), inter-molt stage; (3), pre-molt stage

activity of the $20 \mathrm{~S}$ proteasome. At the highest concentration of $50 \mu \mathrm{mol} 1^{-1}$, only $3 \%$ of the initial activity remained. The trypsin-like activity was inhibited by $75 \%$ at the highest epoxomicin concentration of $100 \mu \mathrm{mol}^{-1}$.

In the gastric fluids of the adult European lobsters, the trypsin-like, chymotrypsin-like and PGPH-like activities were not significantly affected by epoxomicin (Fig. 5a). The chymotrypsin-like activity was only reduced by $3 \%$. The trypsin-like activity (103\%) and the PGPH activity $(104 \%)$ were slightly higher than in the uninhibited assays.

In contrast to the gastric fluid, the activities of the larval and juvenile lobster samples were highly affected by the inhibitor as well as by the activator (Fig. 5b).

The chymotrypsin-like activities of all investigated stages were inhibited by more than $90 \%$. The highest inhibition occurred in the $\mathrm{Z} 3$ stage where only $5.6 \%$ of the initial activity remained. The average inhibition amounted to $90.7 \%$. No significant differences appeared between the stages. The trypsin-like activity was inhibited on average by about $75 \%$. As in the chymotrypsin-like activity, no differences between the stages were detected. The endogenous activator complex PA28 enhanced PGPH activity on average by $45 \%$.

Enzymatic activities of the 20S- and 26S proteasome

The catalytic activities of the three active sites of the $20 \mathrm{~S}$ proteasome changed significantly within the larval development. The average trypsin-like, chymotrypsin-like and PGPH-like activities increased within the Z1 stages and remained at a high level until Z3. All three activities decreased significantly when the larvae developed into the 
Fig. 4 Inhibition of the $20 \mathrm{~S}$ proteasomal activity by different concentrations of epoxomicin. The residual activities (\%) are presented for the chymotrypsin-like activity (a) and for the trypsin-like activities (b) (a)

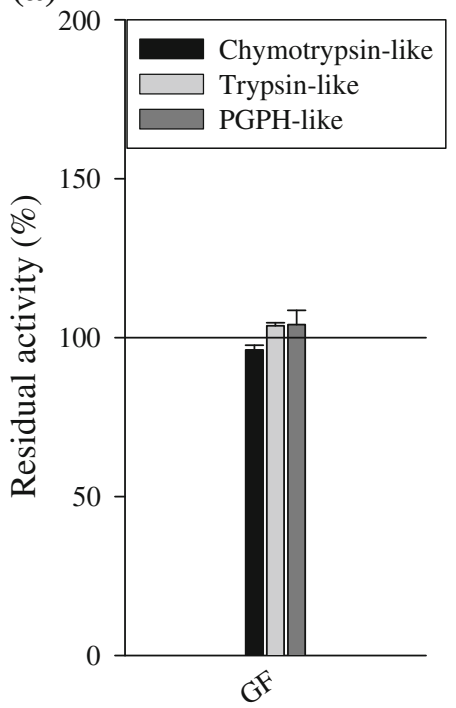

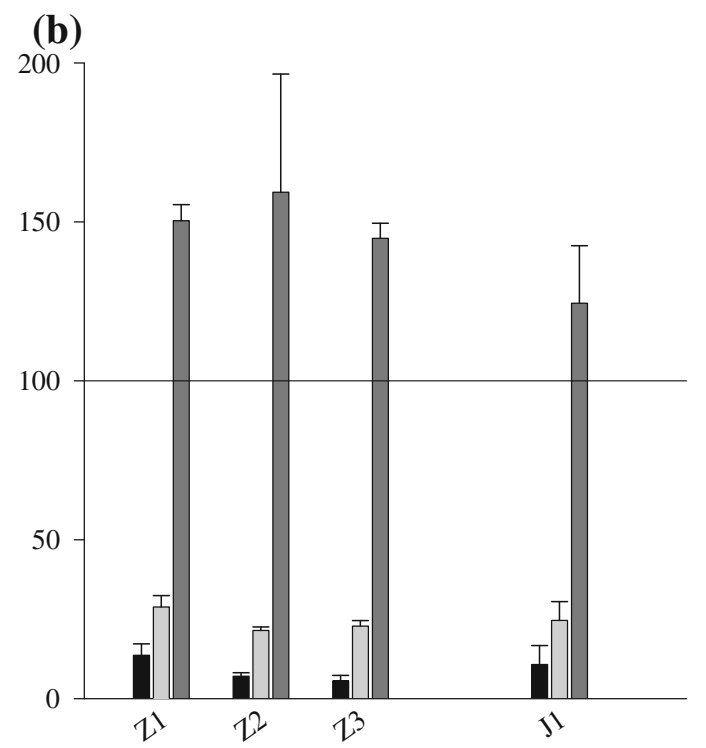

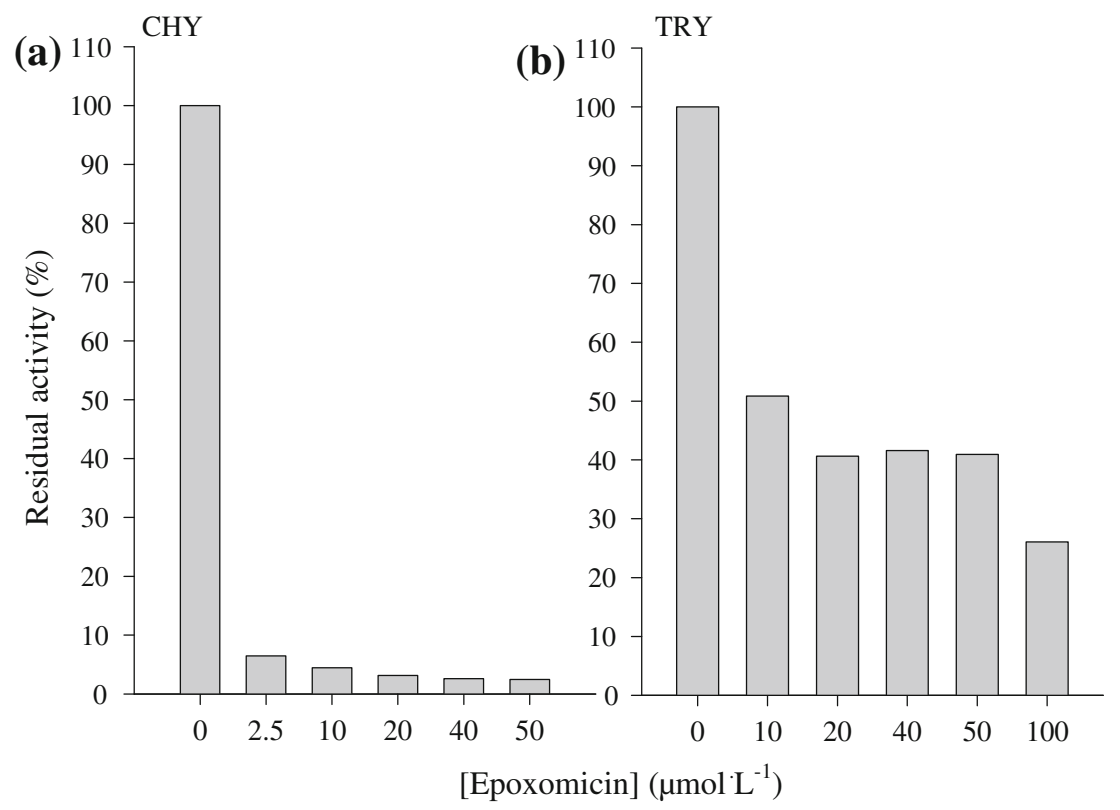

Fig. 5 Effects of epoxomicin and PA28 on the $20 \mathrm{~S}$

proteasomal activities of larvae and adult lobsters. a Impact on the digestive enzymes trypsinlike, chymotrypsin-like and PGPH activity in the gastric fluid (GF) of adult European lobsters $(n=3)$. b The effect of epoxomicin and PA28 onto the three proteasomal activities of the larval (Z1-Z3) and the juvenile stage (J1). Values are expressed as mean of remaining activity $(\%) \pm \operatorname{SEM}(n=30$ per stage). The activities of the untreated samples were set as $100 \%$, and the remaining activities were calculated accordingly juvenile stage. A similar pattern was present in the chymotrypsin-like activities of the $26 \mathrm{~S}$ proteasome. Again, the highest activities appeared in the $\mathrm{Z} 2$ and $\mathrm{Z} 3$ stages.

Changes in activities were detected between the different molt stages (Fig. 6a-c). The chymotrypsin-like activity of the $20 \mathrm{~S}$ proteasome increased within $\mathrm{Z} 1$ individuals from initially $0.09 \mathrm{U} \mathrm{g}_{\text {prt }}^{-1}$ and reached the highest in postmolt $\mathrm{Z} 2$ individuals with $0.30 \mathrm{U} \mathrm{g}_{\text {prt }}^{-1}$ (Fig. 6a). Then, the activity decreased drastically in inter-molt individuals ( $\left.0.12 \mathrm{U} \mathrm{g} \mathrm{g}_{\mathrm{prt}}^{-1}\right)$, but reached the highest again in the subsequent pre-molt individuals. Although the activity did not change significantly within Z3 molt stages, a decreasing trend was evident. This trend distinctly continued in the juvenile stage where the activities decreased from
$0.13 \mathrm{U} \mathrm{g}_{\text {prt }}^{-1}$ in post-molt individuals to $0.04 \mathrm{U} \mathrm{g}_{\text {prt }}^{-1}$ in intermolt juvenile lobsters.

Similar trends were also found for the trypsin-like (Fig. 6b) and the PGPH-like activities (Fig. 6c). In both cases, the activities showed an increasing, though not significant, trend from freshly hatched Z1 larvae to the postmolt individuals of this stage. The inter-molt $\mathrm{Z} 2$ possessed lowest trypsin-like $\left(0.40 \mathrm{U} \mathrm{g}_{\text {prt }}^{-1}\right)$ and PGPH-like $\left(0.23 \mathrm{U} \mathrm{g}_{\mathrm{prt}}^{-1}\right)$ activities and both activities increased again in post-molt $\mathrm{Z3}$ individuals. Furthermore, both activities decreased in inter-molt individuals of Z3. This was followed by an increasing trend in pre-molt individuals again, although these differences were not statistically significant. In the juvenile lobsters, both activities decreased again. 

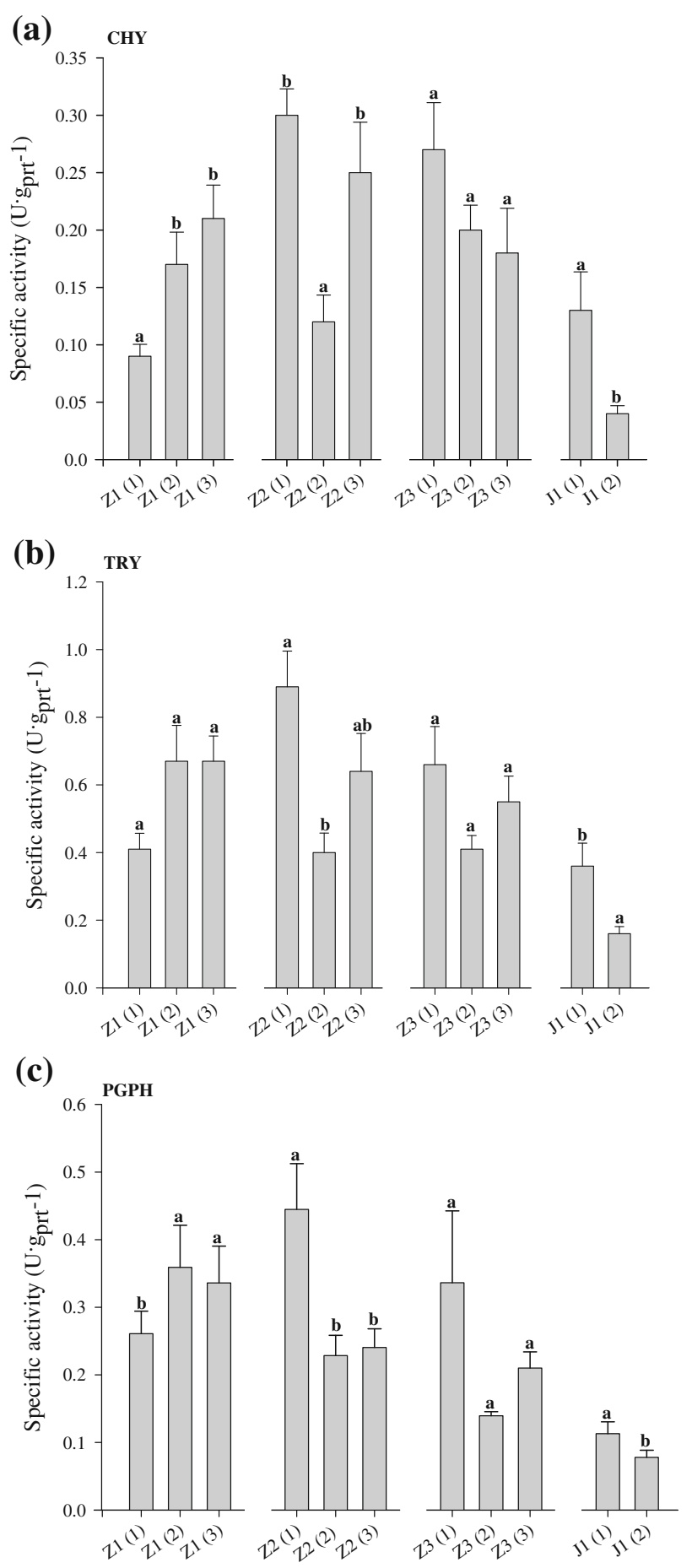

Fig. 6 Chymotrypsin-like (a), trypsin-like (b) and PGPH-like (c) activities of the $20 \mathrm{~S}$ proteasome of the investigated larval and juvenile stages $(n=10$, mean \pm SEM). Different letters indicate significant differences within the respective stages $(p<0.05)$

The chymotrypsin-like activities of the $26 \mathrm{~S}$ proteasome followed a similar pattern as the $20 \mathrm{~S}$ activities. Within the Z1-stage, the activity almost doubled from initially 0.12 to $0.19 \mathrm{U} \mathrm{g} \mathrm{grt}_{\text {prt }}^{-1}$ in the inter-molt stage (Fig. 7). Highest activities were present in the pre-molt phases of Z2 and Z3 (0.23 and $0.24 \mathrm{U} \mathrm{g} \mathrm{grt}_{\text {prt }}^{-1}$, respectively) whereas lowest activities appeared in the inter-molt stages $\left(0.12-0.13 \mathrm{U} \mathrm{g}_{\mathrm{prt}}^{-1}\right)$.

Each stage possessed an individual ratio between the trypsin-like and the chymotrypsin-like activities (Fig. 8). In all stages, the trypsin-like activity dominated. In freshly hatched Z1 individuals, the trypsin-like activity was almost five times higher than the chymotrypsin-like activity. In the subsequent stages, until post-molt $\mathrm{Z} 2$, the ratio of trypsin to chymotrypsin decreased to about 3 . Inter-molt $\mathrm{Z} 2$ animals showed again slightly higher trypsin-like activities. The ratio changed in the following stages in favor of the chymotrypsin-like activity until the larvae developed into the inter-molt Z3 (2.1). The ratio increased significantly to 3.6 in pre-molt $\mathrm{Z} 3$. In the juvenile lobsters, the trypsin-like activity was fourfold higher than the chymotrypsin-like activity.

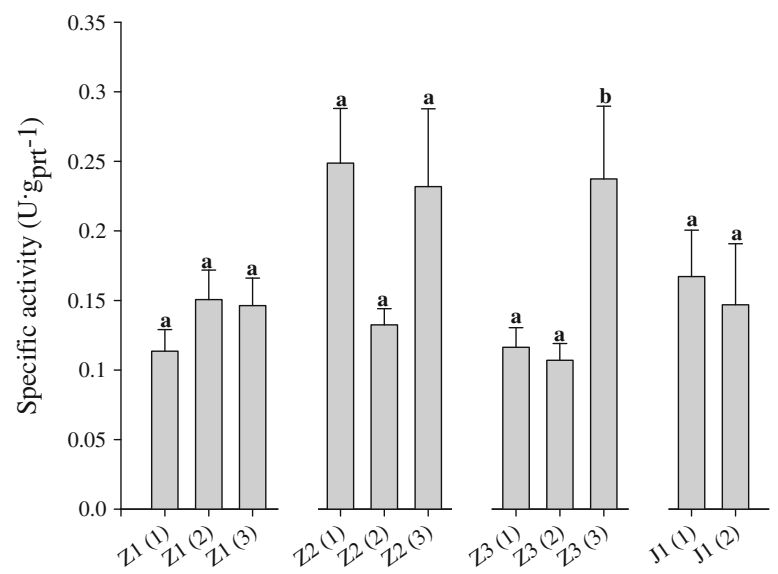

Fig. 7 Chymotrypsin-like activities of the 26S proteasome within the larval and juvenile stages $(n=6$, mean \pm SEM). Different letters indicate significant differences within the single stages $(p<0.05)$

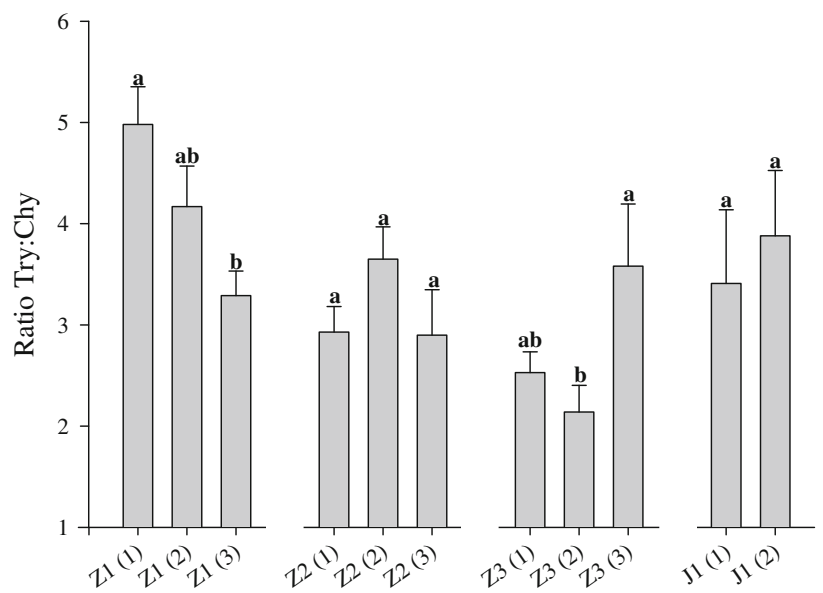

Fig. 8 Ratio between the specific protesomal activities of the trypsinlike site and chymotrypsin-like site. Values are expressed as mean ratio $(n=10$, mean \pm SEM) and different letters indicate significant differences $(p<0.05)$ within the respective stages 


\section{Discussion}

Our results indicate that proteasome plays an important role during the larval development of the European lobster. All catalytically active sites of the $20 \mathrm{~S}$ proteasome as well as the chymotrypsin-like site of the $26 \mathrm{~S}$ proteasome showed high activities within all larval stages. However, in the first juvenile stage, the activities decreased remarkably. Compared to the claw muscle tissue of adult European lobsters, the proteasomal activities of the larvae were several times higher than in adults. Accordingly, it is very likely that these high activities are indicative for the extensive physiological and anatomical changes which the larvae encounter during their development (Charmantier et al. 1991).

It is commonly accepted that the $26 \mathrm{~S}$ proteasome represents the physiological relevant form of the proteolytic multi-enzyme complex (e.g.,Coux et al. 1996; Baumeister et al. 1998; Voges et al. 1999; Galastegui and Groll 2010). However, recent research revealed that the $20 \mathrm{~S}$ unit is active under physiological conditions as well. The 20S proteasome seems capable of degrading protein with unstructured regions or oxidative modification in an ubiquitin-independent manner (Davies 2001; Grune et al. 2003; Liu et al. 2003; Orlowski and Wilk 2003; Asher et al. 2006, Jariel-Encontre et al. 2008). We observed in our studies quite similar pattern of $20 \mathrm{~S}$ and $26 \mathrm{~S}$ chymotrypsin-like activities during the larval development of lobsters. Accordingly, it seems feasible that both the $20 \mathrm{~S}$ and the $26 \mathrm{~S}$ forms of the proteasome may be active during the molt cycles. This observation is in agreement with Mykles 1998, $1999 \mathrm{a}, \mathrm{b}$, who suggested that $20 \mathrm{~S}$ and $26 \mathrm{~S}$ proteasome as well as intracellular $\mathrm{Ca}^{2+}$-dependent proteinases may be involved in the complex pathways of muscle protein catabolism.

The activities varied distinctly between stages and within stages. While within Z1 larvae the activities continuously increased, the activity patterns in $\mathrm{Z} 2$ and $\mathrm{Z3}$ seemed to be more related to the molt stage. It is likely that in the first larval stage, general anabolic processes happen, which may include the formation of effective cellular regulation capacities. The rising activities may reflect the continuous formation of the proteasome after the hatch of the larvae. Lower activities in the inter-molt individuals of Z2 and Z3 may indicate a period of lower protein turnover and, therefore, of lower proteasomal activities due to a down-regulation of enzyme expression. In contrast, the increasing activities particularly of the trypsin-like and the chymotrypsin-like sites of the pre-molt $\mathrm{Z} 2$ may indicate a phase of enhanced protein turnover closely before molt. The increase of activities was most distinct in the pre-molt $\mathrm{Z} 2$. In pre-molt individuals of the $\mathrm{Z} 3$, the activities followed a similar trend but the increase of activities was not statistically significant.
The lessened increase of activities in pre-molt Z3 may be explained by the difficult stage determination of the individuals during sampling. The only possibility we had to identify pre-molt larvae was to take other larvae as a clue and to interpolate the moment of sampling. Larvae of the first two zoea stages pass their development on average within 4 and 8 days, respectively. Furthermore, larvae of these stages molted into the next stage almost simultaneously, which made it relatively easy to collect them at a defined time shortly before molt. In contrast, Z3 larvae needed almost 13 days to reach the next stage and, moreover, they did not molt as simultaneously as the earlier stages did. Thus, individuals which might have been sampled too early caused an underestimation of the enzyme activities.

Similar to the 20S proteasome, which was isolated from adult lobster muscle tissue (Mykles 1997), the proteasome of the larvae possessed highest trypsin-like activities and lower chymotrypsin-like and PGPH-like activities. Remarkably, besides the overall activities, also the ratios between the proteasomal activities changed during the larval development. While in freshly hatched larvae and in juvenile inter-molt individuals the trypsin-like site was dominant, the chymotrypsin-like site seemed to gain relevance in the $\mathrm{Z} 2$ and $\mathrm{Z} 3$ stages.

It was shown in several studies that the proteasome is characterized by high plasticity and, moreover, distinct tissue allocation and specificity (Cardozo et al. 1995; Mykles 1999b; Dahlmann et al. 2000). All catalytic sites of mammal proteasomes are closely interlinked and may allosterically influence each other in a complex way (Kisselev et al. 1999, 2002, 2003, 2006). Drews et al. (2007) reported on proteasome subpopulations with distinct molecular compositions and proteolytic activities. Gomes et al. (2009) compared the murine cardiac and hepatic 20S proteasomes and found an organ-specific organization of the $20 \mathrm{~S}$ proteasome, which was concomitant with a functional heterogeneity in either organ. Similarly, differences in the relative abundance of proteasomal subunits in several mammalian tissues were revealed by Pelletier et al. (2010).

Moreover, ontogenetic variations of proteasomal activities were reported in protists, invertebrates and vertebrates. De Diego et al. (2001) assumed that the enzyme plays an important role during the remodeling phase of Trypanosoma cruzi and indicated a significant role of the proteasome during the development of organisms. In the arthropod Drosophila melanogaster, a cell-specific accumulation of proteasome was reported during the early development (Klein et al. 1990). During embryogenesis, proteasomes were present in proliferating cells and accumulation and turnover were differentially regulated. Klein et al. (1990), moreover, suggested that the proteasomes 
may serve different proteolytic processes and may be involved in cell-specific proteolytic events. Haass and Kloetzel (1989) raised the possibility that both in vivo proteolytic activity and the in vitro substrate specificity of the proteasome may be controlled by modifications of the subunit composition during the development. Ádám et al. (2004) studied the sub-cellular distribution of the $26 \mathrm{~S}$ proteasome in ovarian tissues of D. melanogaster and concluded that also the sub-cellular distribution of the $26 \mathrm{~S}$ proteasome is strictly tissue- and developmental stage dependent. Verras et al. (2008) showed that the expression of an $\alpha 5$-subunit of the $20 \mathrm{~S}$ proteasome is up-regulated before mid-embryogenesis and at the onset of metamorphosis in the fruit fly Ceratitis capitata.

Ahn et al. (1991) described tissue-specific changes in the enzymatic activities and the subunit pattern of the $20 \mathrm{~S}$ proteasome during the embryonic development of chick. In the muscle tissue, overall peptide hydrolysis decreased between day 8 and day 20 of the embryonic development but, exceptionally, chymotrypsin-like activity increased between day 8 and day 12. Moreover, proteasomal casein degradation increased during the experiment. The authors concluded that proteasomal activities were under developmental regulation. Distinct changes in proteasomal activities also appeared in the liver tissue, but were not present in the brain tissue. Hong et al. (1994) found significantly different subunit pattern of proteasomes, which the authors isolated from the muscles, liver and the brain of chicken. Moreover, the proteasomes from embryonic tissues and adult tissues differed from each other indicating that proteasomal activities and subunit patterns are tissue specific and under developmental control.

Our results on lobster larvae complement remarkably the above listed findings in invertebrates and vertebrates. Accordingly, the changes in the enzymatic activities and variations in the ratios of trypsin-like and chymotrypsinlike activities of the $20 \mathrm{~S}$ proteasome seems indicative of functional variations of the proteasome during the larval development of lobsters. During the molt cycle and, particularly, during ecdysis, the claw muscle tissue undergoes substantial changes. The enormous reduction of claw muscle tissue prior to each molt confront adult lobsters with serious degradation- and remodeling processes. Although the muscle mass has to be reduced so that the tissue fits through the narrow joint particularly between the ischium and the merus, the muscle has to maintain its contractile function. This is achieved through a distinct remodeling of the myofibrillar structures (Mykles and Skinner 1981; Ismail and Mykles 1992; Covi et al. 2010). Surprisingly, the protein synthesis in the claw tissues is not reduced in pre-molt crustaceans, but instead significantly increased (El Haj et al. 1996; Mykles 1997). The reason for the steady protein synthesis is a complex mechanism to re- modulate the myofibrillar structures and to reduce the muscle tissue while the contractile function remains unimpaired (Mykles and Skinner 1981). We assume that this mechanism, as it represents a period of enhanced protein turnover, will strongly depend on the balanced interplay of proteasomal activities. The proteasome is one of the main regulators of the cell-cycle (Richter-Ruoff and Wolf 1993; Naujokat and Hoffmann 2002), differentiation processes such as remodeling (De Diego et al. 2001) and growth. Therefore, it seems likely that especially in the developmental stages which are characterized by high mitotic activity, growth and high transcription rates might demand an active and regulating proteasome.

In conclusion, elevated $20 \mathrm{~S}$ and $26 \mathrm{~S}$ proteasome activities clearly indicate an important contribution of the proteasome pathway in the larval development of clawed lobsters, most likely in the re-organization of muscle tissue during molt and growth. Beside the general increase of the proteolytic enzyme activities, the proteasome seems adjusted probably to better cope with higher protein turnover rates during the entire larval development. The detailed mechanisms and particularly the interplay between the $\mathrm{Ca}^{2+}$-dependent calpain proteases and the proteasome need further investigation.

Acknowledgments We are grateful to Dr. Isabel Schmalenbach from the Marine Station Helgoland for providing the lobster larvae and to Kristine Reuter for laboratory assistance.

\section{References}

Ádám G, Gausz J, Noselli S, Kurucz E, Andó I, Udvardy A (2004) Tissue and developmental stage-dependent changes in the subcellular localization of the $26 \mathrm{~S}$ proteasome in the ovary of Drosophila melanogaster. Gene Expr Patterns 4:329-333

Ahn JY, Hong SO, Kwak KB, Kang SS, Tanaka K, Ichihara A, Ha DB, Chung CH (1991) Developmental regulation of proteolytic activities and subunit pattern of $20 \mathrm{~S}$ proteasome in chick embryonic muscle. J Biol Chem 266:15746-15749

Asher G, Reuven N, Shaul Y (2006) 20S proteasome and protein degradation "by default". BioEssays 28:844-849

Baumeister W, Walz J, Zühl F, Seemüller E (1998) The proteasome: paradigm of a self-compartmentalizing protease. Cell 92:367-380

Bradford M (1976) A rapid and sensitive method for the quantification of microgram quantities of protein utilizing the principle of protein-dye binding. Anal Biochem 72:248-256

Cardozo C, Eleuteri AM, Orlowski M (1995) Differences in catalytic activities and subunit pattern of multicatalytic proteinase complexes (proteasomes) isolated from bovine pituitary, lung and liver. J Biol Chem 270:22645-22651

Charmantier G, Charmantier-Daures M, Aiken DE (1991) Metamorphosis in the lobster Homarus (Decapoda): a review. J Crust Biol 11:481-495

Coux O, Tanaka K, Goldberg AL (1996) Structure and function of the $20 \mathrm{~S}$ and the 26S proteasomes. Annu Rev Biochem 65:801-847

Covi JA, Bader BD, Chang ES, Mykles DL (2010) Molt cycle regulation of protein synthesis in skeletal muscle of the blackback land crab, Gecarcinus lateralis, and the differential 
expression of a myostatin-like factor during atrophy induced by molting or unweighting. J Exp Biol 213:172-183

Dahlmann B, Ruppert T, Kuehn LO, Merforth S, Kloetzel PM (2000) Different proteasome subtypes in a single tissue exhibit different enzymatic properties. J Mol Biol 303:643-653

Davies KJA (2001) Degradation of oxidized proteins by the $20 \mathrm{~S}$ proteasome. Biochimie 83:301-310

De Diego JL, Katz JM, Marshall P, Gutierrez B, Manning JE, Nussenzweig V, Gondalez J (2001) The ubiquitin-proteasome pathway plays an essential role in proteolysis during Trypanosoma cruzi remodeling. Biochemistry 40:1053-1062

De Mot R, Nagy I, Walz J, Baumeister W (1999) Proteasomes and other self-compartmentalizing proteases in prokaryotes. Trends Microbiol 7:88-92

Drews O, Wildgruber R, Zong C, Sukop U, Nissum M, Weber G, Gomes AV, Ping P (2007) Mammalian proteasome subpopulations with distinct molecular compositions and proteolytic activities. Mol Cell Proteomics 6:2021-2031

El Haj A, Clarke S, Harrison P, Chang E (1996) In vivo muscle protein synthesis rates in the American lobster Homarus americanus during the molt cycle and in response to 20-hydroxyecdysone. J Exp Biol 199:579-585

Frisan F, Levitsky V, Polack A, Masucci MG (1998) Phenotypedependent differences in proteasome subunit composition and cleavage specificity in B cell lines. J Immunol 160:3281-3289

Galastegui N, Groll M (2010) The 26S proteasome: assembly and function of a destructive machine. Trends Biochem Sci 35:634-642

Gomes AV, Young GW, Wang Y, Zong C, Eghbali M, Drews O, Lu $\mathrm{H}$, Stefani E, Ping P (2009) Contrasting proteome biology and functional heterogeneity of the $20 \mathrm{~S}$ proteasome complexes in mammalian tissues. Mol Cell Proteomics 8:302-315

Götze S, Saborowski R (2011) NanoDrop fluorometry adopted for microassays of proteasomal enzyme activities. Anal Biochem 413:203-205. doi:10.1016/j.ab.2011.02.023

Grune T, Merker K, Sandig G, Davies KJA (2003) Selective degradation of oxidatively modified protein substrates by the proteasome. Biochem Biophys Res Comm 305:709-718

Haass C, Kloetzel PM (1989) The drosophila proteasome undergoes changes in its subunit pattern during development. Exp Cell Res 180:243-252

Hochstrasser M (1995) Ubiquitin, proteasomes, and the regulation of intracellular protein degradation. Curr Op Cell Biol 7:215-223

Hong SO, Ahn JY, Lee CS, Kang MS, Ha DB, Tanaka K, Chung CH (1994) Tissue-specific expression of the subunits of chick $20 \mathrm{~S}$ proteasomes. Biochem Mol Biol Int 32:723-729

Husom AD, Peters EA, Kolling EA, Fugere NA, Thompson LV, Ferrington DA (2003) Altered proteasome function and subunit composition in aged muscle. Arch Biochem Biophys 421:67-76

Ismail SZM, Mykles DL (1992) Differential molt-induced atrophy in the dimorphic claws of the male fiddler crabs, Uca pugnax. J Exp Zool 263:18-31

Jariel-Encontre I, Bossis G, Piechaczyk M (2008) Ubiquitin independent degradation of proteins by the proteasome. Biochem Biophys Acta Rec Cancer 1786:153-177

Kisselev AF, Goldberg AL (2001) Proteasome inhibitors: from research tools to drug candidates. Chem Biol 8:739-758

Kisselev AF, Akopian TN, Castillo V, Goldberg AL (1999) Proteasome active sites allosterically regulate each other, suggesting a cyclical bite-chew mechanism for protein breakdown. Mol Cell 4:395-402

Kisselev AF, Kaganowich D, Goldberg AL (2002) Binding of hydrophobic peptides to several non-catalytic sites promotes peptide hydrolysis by all active sites of $20 \mathrm{~S}$ proteasomes. Evidence for peptide-induced channel opening in the $\alpha$-rings. J Biol Chem 277:22260-22270
Kisselev AF, Garcia-Calvo M, Overkleeeft HS, Peterson E, Pennington MW, Ploegh HL, Thornberry NA, Goldberg AL (2003) The caspase-like sites of proteasomes, their substrate specificity, new inhibitors and substrates, and allosteric interactions with the trypsin-like sites. J Biol Chem 278:35869-35877

Kisselev A, Callard A, Goldberg AL (2006) Importance of the different proteolytic sites of the proteasome and the efficacy of inhibitors varies with the protein substrate. J Biol Chem 281:8582-8590

Klein U, Gernold M, Kloetzel P-M (1990) Cell-specific accumulation of Drosophila proteasome (MCP) during early development. Journal Cell Biol 111:2275-2282

Koenders A, Yu X, Chang ES, Mykles DL (2002) Ubiquitin and actin expression in claw muscles of land crab, Gecarcinus lateralis, and American lobster, Homarus americanus: differential expression of ubiquitin in two slow muscle fiber types during moltinduced atrophy. J Exp Zool 292:618-632

Liu C-W, Corboy MJ, DeMartino GN, Thomas PJ (2003) Endoproteolytic activity of the proteasome. Science 299:408-411

Meng L, Mohan R, Kwork BHB, Elofsson M, Sin N, Crews CM (1999) Epoxomicin, a potent and selective proteasome inhibitor, exhibits in vivo anti-inflammatory activity. Proc Natl Acad Sci USA 96:10403-10408

Mykles DL (1990) Calcium-dependent proteolysis in crustacean claw closer muscle maintained in vitro. J Exp Zool 256:16-30

Mykles DL (1996) Differential effects of bovine PA28 on six peptidase activities of the lobster muscle proteasome (MCP). Arch Biochem Biophys 325:77-81

Mykles DL (1997) Biochemical properties of insect and crustacean proteasomes. Mol Biol Rep 24:133-138

Mykles DL (1998) Intracellular proteinases of invertebrates: calciumdependent and proteasome/ubiquitin-dependent systems. Int Rev Cytol 184:157-289

Mykles DL (1999a) Proteolytic processes underlying molt-induced claw muscle atrophy in decapod crustaceans. Am Zool 39:541-551

Mykles DL (1999b) Structure and functions of arthropod proteasomes. Mol Biol Rep 26:103-111

Mykles DL, Haire MF (1991) Sodium dodecyl sulfate and heat induce two distinct forms of lobster muscle multicatalytic proteinase: the heat-activated form degrades myofibrillar proteins. Arch Biochem Biophys 288:543-551

Mykles DL, Skinner DM (1981) Preferential loss of thin filaments during molt-induced atrophy in crab claw muscle. J Ultrastruc Res 75:314-325

Naujokat C, Hoffmann S (2002) Role and function of the 26S proteasome in proliferation and apoptosis. Lab Invest 82:965-980

Orlowski M, Wilk S (2003) Ubiquitin-independent proteolytic function of the proteasome. Arch Biochem Biophys 415:1-5

Pelletier S, Schuurman KG, Berkers CR, Ovaa H, Heck AJR, Raijmakers R (2010) Quantifying cross-tissue diversity in proteasome complexes by mass spectrometry. Mol BioSyst 6:1450-1453

Richter-Ruoff B, Wolf DH (1993) Proteasome and cell cycle: evidence for a regulatory role of the proteasome on mitotic cyclins in yeast. FEBS Lett 336:34-36

Schmalenbach I, Fanke HD (2010) Potential impact of climate warming on the recruitment of an economically and ecologically species, the European lobster (Homarus gammarus) at Helgoland, North Sea. Mar Biol 157:1127-1135

Shean BS, Mykles DL (1995) Polyubiquitin in crustacean striated muscle: increased expression and conjugation during moltinduced claw muscle atrophy. Biochim Biophys Acta 1264:312-322

Skinner DM (1966) Macromolecular changes associated with the growth of crustacean tissues. Am Zool 6:235-242 
Verras M, Gourzi P, Kalosaka K, Zacharopoulou A, Mintzas AC (2008) cDNA cloning, characterization, and developmental expression of the $20 \mathrm{~S}$ proteasome $\alpha 5$ subunit in the Mediterranean fruit fly Ceratitis capitata. Arch Insect Biochem Physiol 67:120-129
Voges D, Zwickel P, Baumeister W (1999) The 26S proteasome: a molecular machine designed for controlled proteolysis. An Rev Biochem 68:1015-1068 